\title{
Clinical and genetic factors associated with increased risk of severe liver toxicity in a monocentric cohort of HIV positive patients receiving nevirapine-based antiretroviral therapy
}

Andrea Giacomelli ${ }^{1 *}$ (D), Agostino Riva ${ }^{1}$, Felicia Stefania Falvella ${ }^{2}$, Maria Letizia Oreni ${ }^{1}$, Dario Cattaneo ${ }^{2}$, Stefania Cheli ${ }^{2}$, Giulia Renisi ${ }^{1}$, Valentina Di Cristo ${ }^{1}$, Angelica Lupo ${ }^{1}$, Emilio Clementi ${ }^{2,3}$, Stefano Rusconi ${ }^{1}$, Massimo Galli ${ }^{1}$ and Anna Lisa Ridolfo ${ }^{1}$

\begin{abstract}
Background: Nevirapine has been used as antiretroviral agent since early ' 90 . Although nevirapine is not currently recommended in initial anti-HIV regimens, its use remains consistent in a certain number of HIV-1-positive subjects. Thus, our aim was to determine clinical and genetic factors involved in the development of severe nevirapine induced liver toxicity.

Methods: We retrospectively analyzed all HIV positive patients who were followed at the Infectious Diseases Unit, DIBIC Luigi Sacco, University of Milan from May 2011 to December 2015. All patients treated with nevirapine who underwent a genotyping for the functional variants mapping into ABCB1, CYP2B6, CYP3A4 and CYP3A5 genes were included in the analysis. Severe hepatotoxicity was defined as ACTG grade 3-4 AST/ALT increase during the first three months of nevirapine treatment. The causality assessment between NVP exposure and drug-induced liver injury was performed by using the updated Roussel Uclaf Causality Assessment Methods. Hardy Weinberg equilibrium was tested by $x^{2}$ test. A multivariable logistic regression model was constructed using a backward elimination method.
\end{abstract}

Results: Three hundred and sixty-two patients were included in the analysis, of which 8 (2.2\%) experienced a severe liver toxicity. We observed no differences between patients with and without liver toxicity as regards gender, ethnicity, age and immune-virological status. A higher prevalence of HCV coinfection (75.0\% vs 30.2\%; $p=.0013$ ) and higher baseline AST (58 IU/L vs $26 \mathrm{IU} / \mathrm{L} ; p=0.041$ ) and ALT (82 IU/L vs $27 \mathrm{IU} / \mathrm{L} ; p=0.047$ ) median levels were observed in patients with liver toxicity vs those without toxicity. The genotypes CT/TT at ABCB1 rs1045642 single nucleotide polymorphism (SNP), showed a protective effect for liver toxicity when compared with genotype CC $(\mathrm{OR}=0.18,95 \% \mathrm{Cl}$ $0.04-0.76 ; p=0.020$ ) in univariate analysis. In the multivariate model, HCV coinfection was independently associated with higher risk of developing liver toxicity $(\mathrm{aOR}=8.00,95 \% \mathrm{Cl} 1.27-50.29 ; p=0.027)$, whereas $\mathrm{ABCB} 1 \mathrm{rs} 1045642 \mathrm{CT} / \mathrm{TT}$ genotypes $(\mathrm{aOR}=0.10,95 \% \mathrm{Cl} 0.02-0.47 ; p=0.004)$ was associated with a lower risk.

(Continued on next page)

\footnotetext{
* Correspondence: andrea.giacomelli@unimi.it; dott.giacomelli@gmail.com ${ }^{1}$ Infectious Diseases Unit, DIBIC Luigi Sacco - University of Milan, Via G.B. Grassi, 74, 20157 Milan, Italy

Full list of author information is available at the end of the article
}

(c) The Author(s). 2018 Open Access This article is distributed under the terms of the Creative Commons Attribution 4.0 International License (http://creativecommons.org/licenses/by/4.0/), which permits unrestricted use, distribution, and reproduction in any medium, provided you give appropriate credit to the original author(s) and the source, provide a link to the Creative Commons license, and indicate if changes were made. The Creative Commons Public Domain Dedication waiver (http://creativecommons.org/publicdomain/zero/1.0/) applies to the data made available in this article, unless otherwise stated. 
(Continued from previous page)

Conclusions: According to our findings HCV coinfection and ABCB1 rs1045642 SNP represent independent determinants of severe liver toxicity related to nevirapine. This genetic evaluation could be included as toxicity assessment in HIV-1-positive subjects treated with nevirapine.

Keywords: Nevirapine, Pharmacogenetic, Hepatotoxicity, ABCB1

\section{Background}

Nevirapine (NVP) is a potent non-nucleoside reverse transcriptase inhibitor widely prescribed in low-income countries for HIV treatment and prevention of motherto-child transmission of HIV [1]. In high-resource countries, NVP is no longer included among antiretrovirals recommended for initial antiretroviral treatment (ART), although it still remains a valid component of regimens used as ART simplification strategy due to its high efficacy, good metabolic profile, convenience, and low cost [2-4].

Although generally well tolerated and effective, some individuals exposed to NVP develop in the short-term hypersensitivity reactions which can manifest as hepatotoxicity and/or severe cutaneous adverse reactions [5]. Hepatotoxicity, in particular, has been reported more commonly with NVP than with other antiretroviral drugs $[6,7]$. Higher baseline and nadir CD4 cell count have been found to independently influence the risk of NVP-related adverse reactions and the use of NVP in naive women (with CD4 $>250$ cells/uL) and males (with CD4 > 400 cells/uL) is disallowed [8]. The role of the immune system, i.e. higher CD4 cells count, in the development of NVP induced skin and liver toxicity is corroborated by the higher incidence of these events in HIV negative patients receiving NVP as a component of post exposure prophylaxis [5]. Nevertheless, when NVP is used in ART-experienced patients with a controlled viremia the risk of development hepatic or cutaneous adverse events significantly decrease and there is no evident association with CD4 cell count [9-11].

A series of demographic and clinical factors have been found to correlate with an increased risk of NVP-toxicity. In particular, risk factors for ALT and AST elevations during NVP therapy included alteration of liver enzymes before NVP start, co-infection with hepatitis $\mathrm{B}$ or hepatitis $\mathrm{C}$ viruses, female gender and low body weight $[6,12]$.

A number of studies have also investigated the possible predictive role of genetic polymorphisms of CYP enzymes or drug-transporters involved in NVP metabolism in predisposing to NVP-related adverse effects. NVP is metabolized by cytochrome P450 enzymes CYP2B6 and CYP3A4 with a minor contribution from CYP3A5 [13]. Single nucleotide polymorphisms (SNPs) have been found to impact NVP pharmacokinetics in ethnic mix populations [14-16]. The genotype TT (c.516/ rs3745274) in the CYP2B6 gene, in particular, has been associated with higher plasma concentrations of NVP and its possible role in increasing the risk of hepatotoxicity has been hypothesized [14]. However, there is contrasting evidence of interactions between the presence of variant alleles of CYP2B6 and the development of NVP-induced hepatotoxicity [17-19]. The role of CYP3A4 and CYP3A5 variants in determining NVP plasma concentration and the development of liver toxicity is more controversial, with only one report of association between CYP3A5 variants and transaminase values in African patients exposed to NVP [20]. Moreover, although effects of the efflux transporter P-glycoprotein encoded by the ATP Binding Cassette Subfamily B Member 1 (ABCB1) gene on NVP pharmacokinetics remains controversial, two studies have found a protective effect of ABCB1 c.3435 $\mathrm{T}$ allele against NVP-related hepatotoxicity $[19,20]$.

The majority of the studies that evaluated the correlation between pharmacogenetic profiles and NVP-related hepatotoxicity have been performed mainly on African population. However, genetic variant frequencies can differ markedly between different populations and only few data are available on the mentioned pharmacogenetic profiles in non-African populations.

With this in mind, we assessed clinical and pharmacogenetic factors associated with the risk of severe NVP induced liver toxicity in a population of HIV-positive patients attending a clinical center in Italy.

\section{Methods}

This study was conducted on a cohort of adult HIV-positive patients attending the Infectious Diseases Unit, DIBIC Luigi Sacco, University of Milan between May 12011 and December 31 2015. Patients who have ever received or were receiving a NVP-containing cART at our clinical center were eligible for the analysis.

Patient's demographic (age, gender, and ethnicity), epidemiological (HIV acquisition risk) and clinical (CDC stage, body mass index, coinfections, previous and current antiretroviral regimens, immune-virological and hemato-biochemical parameters) data registered during medical visits (on average every three months) are 
routinely collected in a structured database, allowing the use of the database for clinical, epidemiological or therapeutic studies.

Severe hepatotoxicity was defined as ACTG grade 3-4 AST and/or ALT increase (AST or ALT elevation above 5 time the upper reference limit) during the first three months of nevirapine treatment. The causality assessment between NVP exposure and drug-induced liver injury was performed by using the updated Roussel Uclaf Causality Assessment Methods (RUCAM) [21]. According to the RUCAM, patients were firstly assessed for hepatocellular, cholestatic or mixed liver injury. Subsequently, the score was applied and single cases of NVP-induced liver injury were classified accordingly to the RUCAM total score interpretation and causality grading: $\leq 0$, excluded; $1-2$, unlikely; $3-5$, possible; $6-8$, probable and $\geq 9$ highly probable [21].

All patients who met the inclusion criteria underwent a genotyping for the functional variants mapping in ABCB1 (c.3435/rs1045642), CYP2B6 (c.516/rs3745274), CYP3A5 (*3/rs776746) and CYP3A4 (*22/rs35599367) genes. Genomic DNA was isolated from peripheral blood cells using an automatic DNA extraction system (Maxwell ${ }^{\circ} 16$ System, Promega) according to the manufacturer's instructions. All genotypes were determined by Real-Time PCR, using a panel of LightSNiP from TIB-MolBiol (assays based on SimpleProbe ${ }^{\circ}$ ). At the end of the amplification a melting curve analysis was performed (LightCycler 480, Roche).

\section{Statistical analysis}

Baseline clinical characteristics and genotypes of the two groups of interest, i.e. patients who developed severe hepatotoxicity and those who did not, were compared using the $\chi^{2}$ or Fisher's exact test for categorical variables and the Mann-Whitney test for continuous variables.

Hardy Weinberg equilibrium was tested by $x^{2}$ test.

The association of clinical and genotypic variables with the development of sever liver toxicity was tested by means of a univariate logistic regression model, and all variables were incorporated into a multivariate logistic regression model with a backward elimination method. Statistical significance was defined at 2 -sided $P$ value $<0.05$. The risks were expressed as adjusted odds ratios (aOR) with relative confidence intervals $(95 \% \mathrm{CI})$. To perform statistical analysis we used the SAS software version 9.3.

The study was reviewed and approved by our ethics committee (Comitato Etico Interaziendale, Milano area 1 ); all subjects signed a dedicated informed consent.

\section{Results}

A total of 362 patients were included in the analysis. Most of them were ART-experienced at the time of initiation of NVP-containing regimen, whereas a minority
(16.1\%) were ART-naïve. Overall 8 (2.2\%) patients experienced a severe liver toxicity during the first three months from NVP initiation. Table 1 shows the comparison of patients who experienced a severe hepatotoxicity and those who did not. There was no significant difference as regards gender, ethnicity, age and baseline immune-virological status between the two groups although females showed a trend towards a higher frequency of NVP-induced hepatotoxicity $(75.0 \%$ vs $35.9 \%$; $p=0.055)$. Conversely, patients who developed severe hepatotoxicity were more frequently $\mathrm{HCV}$-coinfected (75.0\% vs 30.2\%: $p=0.013$ ), showed higher baseline AST and ALT median levels (58 IU/L vs $26 \mathrm{IU} / \mathrm{L} p=0.041$, $82 \mathrm{IU} / \mathrm{L}$ vs $27 \mathrm{IU} / \mathrm{L} p=0.047$, respectively), and a lower median baseline body mass index value $\left(19.9 \mathrm{~kg} / \mathrm{m}^{2}\right.$ vs $\left.22.6 \mathrm{~kg} / \mathrm{m}^{2} ; p=0.017\right)$.

According to RUCAM, the 8 cases of NVP-induced liver toxicity were classified as hepatocellular injury and the likelihood of NVP-induced liver toxicity resulted possible for 3 patients and probable for 5 patients as shown in Table 2. A brief narration for each of the 8 cases is reported in Table 3.

Distribution of different genotypes of $\mathrm{ABCB} 1$ rs1045642, CYP2B6 rs3745274 and CYP3A4/A5 combined are shown in Table 4. A statistical significant difference was observed in patient with and without NVP-induced hepatotoxicity according to ABCB1 rs1045642 genotypes $(p=0.019)$.

In univariate analysis (Table 5), male gender $(\mathrm{OR}=$ 0.19 95\%CI 0.04-0.94; $p=0.042)$, HCV coinfection (OR $=6.9395 \%$ CI $1.38-34.87 ; p=0.019)$, AST $(\mathrm{OR}=1.02$, 95\%CI 1.01-1.03; $p=0.008)$ and ALT (OR $=1.01,95 \% \mathrm{CI}$ $1.00-1.02 ; p=0.015)$ median level at the beginning of NVP have been associated with an increased risk of severe NVP-induced liver toxicity. On the other hand, genotypes $\mathrm{CT} / \mathrm{TT}$ of $\mathrm{ABCB} 1 \mathrm{rs} 1045642(\mathrm{OR}=0.18,95 \% \mathrm{CI}$ $0.04-0.76 ; p=0.020)$ and greater value of body mass index $(\mathrm{OR}=0.795 \% \mathrm{CI}$ 0.51-0.94, $\mathrm{p}=0.02)$ showed a protective effect.

In the multivariate logistic regression model (Table 5), $\mathrm{HCV}$ coinfection was confirmed to be independently associated with a higher risk of developing liver toxicity $(\mathrm{aOR}=8.00,95 \% \mathrm{CI} 1.27-50.29 ; p=0.027)$, whereas ABCB1 CT/TT genotypes $(\mathrm{aOR}=0.10,95 \% \mathrm{CI} 0.02-0.47$; $p=0.004$ ) has been associated with a lower risk; a higher body mass index (aOR $=0.72$, 95\%CI 0.519 1.000; $p=0.050$ ) has been barely related to a lower risk (Table 5). On the contrary, the association between gender, baseline AST levels and NVP-induced liver toxicity wasn't confirmed in the final multivariate model.

\section{Discussion}

In this study conducted in a monocentric cohort of HIV-1 positive patients exposed to NVP we observed, 
Table 1 Baseline characteristics

\begin{tabular}{|c|c|c|c|c|}
\hline & $\begin{array}{l}\text { Total } \\
n=362\end{array}$ & $\begin{array}{l}\text { Hepatotoxicity } \\
n=8\end{array}$ & $\begin{array}{l}\text { No hepatotoxicity } \\
n=354\end{array}$ & $p^{*}$ \\
\hline Age, median (IQR) & $38.5(33.7-45.8)$ & $39.6(32.7-40.7)$ & $38.5(33.8-45.9)$ & 0.479 \\
\hline Female, n (\%) & $133(36.7)$ & $6(75.0)$ & $127(35.9)$ & 0.055 \\
\hline Naïve patients, n (\%) & $58(16.0)$ & $1(12.5)$ & $57(16.1)$ & 0.783 \\
\hline \multicolumn{5}{|l|}{ Risk group, n (\%) } \\
\hline Eterosexual & $181(50.0)$ & $4(50.0)$ & $177(50.0)$ & \multirow[t]{4}{*}{0.213} \\
\hline MSM & $83(22.9)$ & $0(0.0)$ & $83(23.5)$ & \\
\hline IVDUs & $84(23.2)$ & $4(50.0)$ & $80(22.6)$ & \\
\hline Others & $14(3.9)$ & $0(0.0)$ & $14(3.9)$ & \\
\hline Caucasian, n (\%) & $330(91.1)$ & $7(87.5)$ & $323(91.2)$ & 0.527 \\
\hline BMI, median (IQR) & $22.4(20.5-24.5)$ & $19.9(18.3-22.0)$ & $22.6(20.6-24.5)$ & 0.017 \\
\hline AIDS, n (\%) & $63(17.4)$ & $1(12.5)$ & $62(17.5)$ & 0.999 \\
\hline CD4+/mL, median (IQR) & $436(306-593)$ & $555(479-611)$ & $433(300-592)$ & 0.157 \\
\hline HIV-RNA $\log _{10} \mathrm{cp} / \mathrm{mL}$,median (IQR) & $1.75(0.00-4.09)$ & $0.00(0.00-2.16)$ & $1.79(0.00-4.10)$ & 0.229 \\
\hline HCV coinfection, n (\%) & $131(31.2)$ & $6(75.5)$ & $107(30.2)$ & 0.013 \\
\hline HBV coinfection, n (\%) & $21(5.8)$ & $1(12.5)$ & $20(5.65)$ & 0.383 \\
\hline AST U/L, median (IQR) & $26(20-38)$ & $58(29-92)$ & $26(20-37)$ & 0.041 \\
\hline ALT U/L, median (IQR) & $28(18-50)$ & $82(37-122)$ & $27(18-49)$ & 0.047 \\
\hline \multicolumn{5}{|l|}{ ARV backbone, n (\%) } \\
\hline$A B C$ & $32(8.8)$ & $1(12.5)$ & $31(8.8)$ & \multirow[t]{4}{*}{0.311} \\
\hline AZT/DDI/D4T & $223(61.6)$ & $7(87.5)$ & $216(61.0)$ & \\
\hline TDF & $86(23.7)$ & $0(0.0)$ & $86(24.3)$ & \\
\hline Others & $21(5.8)$ & $0(0.0)$ & $21(5.9)$ & \\
\hline
\end{tabular}

Abbreviations: $n$ number, yrs. years, IQR Inter Quartile Range, MSM Man how have sex with man, IVDUs Intra venous drug users, BMI Body Mass Index, cps copies, $A B C$ abacavir, $T D F$ tenofovir diproxil fumarate. * $p$-values are for $X^{2}$ or Fisher's exact test and Mann-Whitney test

during the first three months of treatment, an incidence of severe liver toxicity of $2.2 \%$. This finding is similar to that reported by other cohorts when NVP was used in $e x$ perienced patients $[10,22]$. We did not observe a significant association between the development of hepatotoxicity and high CD4 cells count at NVP start, supporting the observation of low frequency of NVP induced liver toxicity in experienced patients [10]. The mechanisms involved in the development of severe hepatotoxicity are not well explained and it could be that in patients never exposed to antiretroviral therapy immune-mediated process leading to immune-reconstitution could elicit the development of liver toxicity [23]. On the contrary, in experienced patients with a stable immune-virological situation, hepatotoxicity could be driven by a direct effect of the drug in susceptible patients [24]. We confirm previous findings supporting the importance of $\mathrm{HCV}$ coinfection as independent factor associated to the development of NVP-related liver toxicity; HCV infection could play a direct role causing liver injury and also could interfere with the metabolism of the drug $[8,11,25]$. The enhanced risk of development hepatotoxicity in $\mathrm{HCV}$ coinfected patients treated with NVP seems to be independent from NVP plasmatic concentrations, since comparable NVP concentration are observed in patients with and without $\mathrm{HCV}$ coinfection [26].

A significant correlation between low value of body mass index $(<18.5)$ such as for increased NVP plasma concentration and increased risk for hepatotoxicity has been previously reported $[12,18]$, in our study we observed a trend of body weight in predisposing to NVP-hepatotoxicity albeit not confirmed in the multivariate model.

In accordance with previous studies, we did not found a statistically significant association between polymorphisms in CYPs genes (CYP2B6, CYP3A4, CYP3A5) and the development of severe hepatotoxicity. Although these genes are involved in NVP metabolism [27] and their functional variants may significantly affect NVP plasma concentrations [28-30], their role in predisposing NVP induced hepatotoxicity remains unclear $[19,31]$.

The ABCB1 gene encodes for P-glycoprotein, one of the most important efflux pomp involved in the transport of both NVP and efavirenz and a modification of this protein could determine an alteration in the intracellular concentration of these drugs [32]. 
Table 2 Updated RUCAM for the nevirapine-induced hepatocellular injury with the total scores for each patient

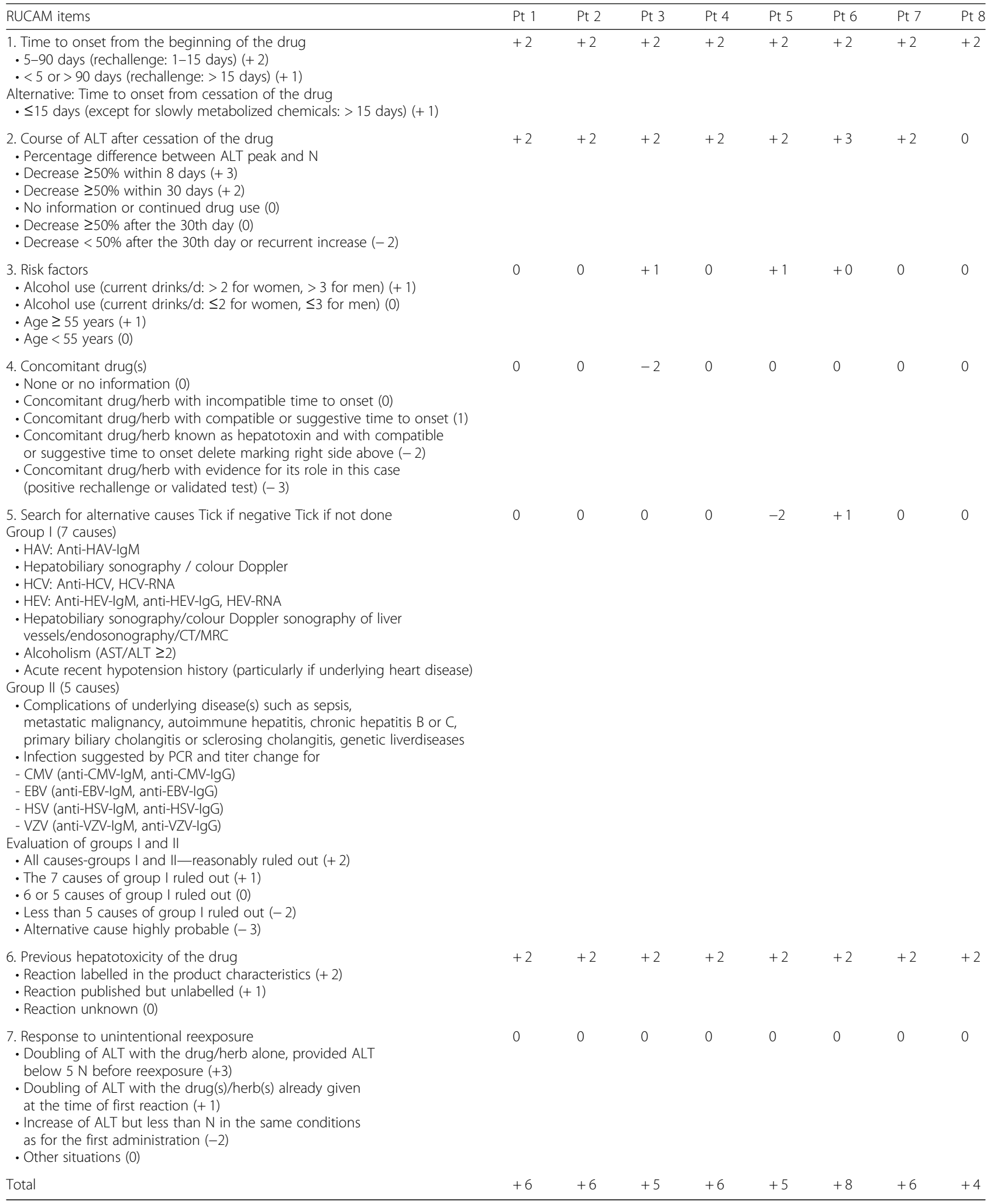

Abbreviations: pt. Patient, ALT Alanine aminotransferase, AST Aspartate aminotransferase, CMV Cytomegalovirus, CT Computer tomography, EBV Epstein Barr virus, HAV Hepatitis A virus, HBC Hepatitis B core, HBsAg Hepatitis B antigen, HBV Hepatitis $B$ virus, HCV Hepatitis C virus, HEV Hepatitis E virus, HSV Herpes simplex virus, MRC Magnetic resonance cholangiography, $N$ upper limit of the normal range, RUCAM Roussel Uclaf Causality Assessment Method, VZV Varicella zoster virus

Total score and resulting causality grading: $\leq 0$, excluded; $1-2$, unlikely; $3-5$, possible; $6-8$, probable; and $\geq 9$, highly probable 
Table 3 Clinical characteristics of the 8 cases of NVP-induced liver injury. ${ }^{*} H L A B 5701$ tested absent

\begin{tabular}{|c|c|c|c|c|c|c|c|c|}
\hline & Pt 1 & Pt 2 & Pt 3 & Pt 4 & Pt 5 & Pt 6 & Pt 7 & Pt 8 \\
\hline HCV coinfection & no & yes & yes & yes & yes & no & yes & yes \\
\hline ARV status & Experienced & Experienced & Experienced & Experienced & Naive & Experienced & Experienced & Experiencec \\
\hline Concomitant ARV & $d 4 T+3 T C$ & $d 4 T+3 T C$ & $A B C^{*}+3 T C$ & $A Z T+3 T C$ & $A Z T+3 T C$ & $\mathrm{~d} 4 \mathrm{~T}+\mathrm{ddi}$ & $A Z T+3 T C$ & $\mathrm{~d} 4 \mathrm{~T}+\mathrm{ddi}$ \\
\hline $\begin{array}{l}\text { NVP exposure before } \\
\text { treatment interruption } \\
\text { (days) }\end{array}$ & 28 & 61 & 29 & 28 & 58 & 28 & 50 & 38 \\
\hline Concomitant medication & none & none & $\begin{array}{l}\text { Vitamin D and } \\
\text { folinic acid }\end{array}$ & none & $\begin{array}{l}\text { Phenobarbital } \\
\text { and alprazolam }\end{array}$ & none & None & Folinic acid \\
\hline Symptoms & $\begin{array}{l}\text { Nausea } \\
\text { and severe } \\
\text { weakness }\end{array}$ & none & Nausea & none & Weakness & none & Nausea & None \\
\hline Required hospitalization & yes & no & yes & no & no & no & no & no \\
\hline Outcome & $\begin{array}{l}\text { Recovered } \\
\text { without } \\
\text { sequelae }\end{array}$ & $\begin{array}{l}\text { Recovered } \\
\text { without } \\
\text { sequelae }\end{array}$ & $\begin{array}{l}\text { Recovered } \\
\text { without } \\
\text { sequelae }\end{array}$ & $\begin{array}{l}\text { Recovered } \\
\text { without } \\
\text { sequelae }\end{array}$ & $\begin{array}{l}\text { Recovered } \\
\text { without } \\
\text { sequelae }\end{array}$ & $\begin{array}{l}\text { Recovered } \\
\text { without } \\
\text { sequelae }\end{array}$ & $\begin{array}{l}\text { Recovered } \\
\text { without } \\
\text { sequelae }\end{array}$ & $\begin{array}{l}\text { Recovered } \\
\text { without } \\
\text { sequelae }\end{array}$ \\
\hline RUCAM & Probable & Probable & Possible & Probable & Possible & Probable & Probable & Possible \\
\hline
\end{tabular}

Abbreviations: Pt Patient, HCV Hepatitis C virus, ARV Antiretroviral, d4T Stavudine, 3TC Lamivudine, ABC Abacavir, AZT Zidovudine, ddi Didanosine, RUCAM Roussel Uclaf Causality Assessment Method

Interestingly, the functional variant c.3435 $\mathrm{C}>\mathrm{T}$ of $\mathrm{ABCB} 1$ gene was associated with an increases risk for severe liver toxicity in a previous study conducted by Hass et al. in South-Africa [19]. Moreover, the variant ABCB1 c.3435 $\mathrm{C}>\mathrm{T}$ resulted protective for NVP-associated hepatic adverse events in another study conducted in Mozambique [20]. No statistically significant association between ABCB1 c.3435 C>T and NVP adverse events was found in another study conducted by Yuan J et al. in an ethnic mixed population. However, these authors found a significant association between ABCB1 c.3435 C>T variant and hepatic adverse events among Africans but not Asians or Caucasians, despite these latter groups showed increased T-allele frequencies [31].

Overall our study, which was conducted on a prevalently European Caucasian population, disagrees with the study by Yan et al. On the contrary it supports the protective role of $\mathrm{T}$ allele of ABCB1 rs1045642 for NVP-hepatotoxicity evidenced by Hass et al. and Ciccacci et al.

The present study has some limitations. In particular, due to the retrospective design we cannot exclude the presence of possible bias related to loss of data. A sub-optimal performance of RUCAM, which is more fitted for a prospective patient evaluation, could be hypothesized because of the

Table 4 Disposition of polymorphisms involved in nevirapine metabolism

\begin{tabular}{|c|c|c|c|c|}
\hline & Total & Hepatotoxicity & No hepatotoxicity & $p^{*}$ \\
\hline & $n=362$ & $n=8$ & $n=354$ & \\
\hline ABCB1 c.3435/rs1045642, n (\%) & & & & 0.019 \\
\hline CC & $86(23.8)$ & $5(5.8)$ & $81(94.2)$ & \\
\hline CT & $178(49.2)$ & $1(0.6)$ & $177(99.4)$ & \\
\hline$\pi$ & $98(27.0)$ & $2(2.0)$ & $96(98.0)$ & \\
\hline CYP2B6 c.516/rs3745274, n (\%) & & & & 0.706 \\
\hline GG & $196(54.1)$ & $6(3.1)$ & $190(96.9)$ & \\
\hline GT & $141(39.0)$ & $2(1.4)$ & $139(98.6)$ & \\
\hline$\pi$ & $25(6.9)$ & $0(0.0)$ & $25(100.0)$ & \\
\hline CYP3A4/A5 **, n (\%) & & & & 0.602 \\
\hline Extensive & $58(16.1)$ & $0(0.0)$ & $58(100.0)$ & \\
\hline Intermediate & $270(74.5)$ & $8(3.0)$ & $262(97.0)$ & \\
\hline Poor & $25(6.9)$ & $0(0.0)$ & $25(100.0)$ & \\
\hline nd & $9(2.5)$ & $0(0.0)$ & $9(100.0)$ & \\
\hline
\end{tabular}

Abbreviations: $n$ number, $n d$ not determined, $A B C B$ ATP Binding Cassette Subfamily B, CYP Cytochrome P450 enzyme 
Table 5 Backward logistic regression of factors involved in nevirapine induced liver toxicity

\begin{tabular}{|c|c|c|c|c|}
\hline & OR $(95 \% \mathrm{Cl})$ & $p$ & aOR $(95 \% \mathrm{Cl})$ & $p$ \\
\hline Male vs Female & $0.19(0.04-0.94)$ & 0.042 & $0.27(0.06-1.30)$ & 0.102 \\
\hline Age ( $\times 1$ year more) & $0.96(0.88-1.04)$ & 0.293 & - & \\
\hline MSM vS HE & $0.24(0.01-4.51)$ & 0.338 & - & \\
\hline IVDUs vs HE & $2.20(0.58-8.41)$ & 0.247 & - & \\
\hline Other vs HE & $1.36(0.06-29.16)$ & 0.844 & - & \\
\hline Caucasian vs Non-Caucasian & $0.67(0.08-5.64)$ & 0.714 & - & \\
\hline BMI (× 1 more) & $0.70(0.51-0.94)$ & 0.020 & $0.72(0.52-1.00)$ & 0.050 \\
\hline Previous AIDS & $0.67(0.08-5.56)$ & 0.713 & - & \\
\hline Previous therapy duration ( $\times 1$ year more) & $1.05(0.90-1.23)$ & 0.518 & - & \\
\hline 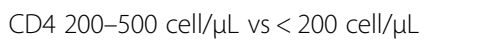 & $1.17(0.05-25.7)$ & 0.920 & $1.51(0.07-32.23)$ & 0.790 \\
\hline CD4 $>500$ cell/ $\mu \mathrm{L}$ vs $<200$ cell $/ \mu \mathrm{L}$ & $3.97(0.21-74.51)$ & 0.357 & $8.12(0.42-156.90)$ & 0.166 \\
\hline HIV-RNA (× $1 \log 10$ more) & $0.80(0.54-1.18)$ & 0.260 & - & \\
\hline AST $(\times 1$ more) & $1.02(1.01-1.03)$ & 0.008 & $1.01(0.99-1.03)$ & 0.144 \\
\hline $\operatorname{ALT}(\times 1$ more $)$ & $1.01(1.00-1.02)$ & 0.015 & - & \\
\hline HCV coinfection & $6.93(1.38-34.87)$ & 0.019 & $8.00(1.27-50.29)$ & 0.027 \\
\hline HBV coinfection & $2.39(0.28-20.36)$ & 0.427 & - & \\
\hline ARV Backbone: AZT/DDI/D4T vs ABC & $0.73(0.12-4.47)$ & 0.731 & - & \\
\hline ARV Backbone: TDF vs ABC & $0.12(0.01-3.141)$ & 0.204 & - & \\
\hline ARV Backbone: Other vs ABC & $0.49(0.02-13.47)$ & 0.672 & - & \\
\hline ABCB1 rs1045642 CT/TT vs CC & $0.18(0.04-0.76)$ & 0.020 & $0.10(0.02-0.47)$ & 0.004 \\
\hline
\end{tabular}

Abbreviations: OR Odds Ratio, aOR adjusted Odds Ratio, $\mathrm{Cl}$ confidence interval, HE Heterosexual, MSM Man how have sex with man, IVDUs Intra venous drug users, $B M I$ Body Mass Index, cps copies, $A B C$ abacavir, TDF tenofovir diproxil fumarate, BMI Body Mass Index, ABCB ATP Binding Cassette Subfamily B

retrospective nature of the study. Moreover, if on one hand the limited number of NVP induced hepatic adverse events supports the good safety profile of this drug in ART-experienced patients, on the other hand our study could not exclude that the prevalence of the investigated polymorphisms could be driven by chance. Moreover, the prevalence of Caucasian ethnicity limited the comparison of our findings between different ethnic groups.

\section{Conclusion}

Beyond to clinical conditions well known to drive the development of hepatotoxicity during NVP treatment, i.e. $\mathrm{HCV}$ coinfection and body mass index, pharmacogenomic profiles could also play a role in this phenomenon. Our results suggest the independent role of ABCB1 rs1045642 as a predictive marker of severe liver toxicity related to NVP. Further validation studies, to assess possible clinical application of this marker in countries in which NVP is still widely used and/or in patients with other risk factors for nevirapine related toxicity, are warranted.

\section{Abbreviations}

ABCB: ATP Binding Cassette Subfamily B; aOR: Adjusted Odds Ratio; ART: Antiretroviral treatment; Cl: Confidence interval; CYP: Cytochrome P450 enzyme; HIV-1: Human immunodeficiency virus type 1; IQR: Inter quartile range; NVP: Nevirapine; OR: Odds Ratio; RUCAM: Roussel Uclaf Causality Assessment Methods; SNPs: Single nucleotide polymorphisms
Acknowledgements

We thank Mrs. Tiziana Formenti for the excellent technical help.

\section{Funding}

No financial support to this study.

\section{Availability of data and materials}

The data sets used and/or analyzed during the current study available from the corresponding author on reasonable request.

\section{Authors' contributions}

$A G, A L R, A R, F S F, M L O, M G, S R$ designed the study. GR, VDC, AL assessed the patient's documentation and evaluated the inclusion in the study. AG, ALR, $G R, V D C, A L$, were involved in data collection and interpretation. FSF, EC, DC, SC performed laboratory analyses. AG, MLO were responsible for the statistical analyses. All authors interpreted the data and drafted the manuscript. All authors have critically revised and approved the final version.

Ethics approval and consent to participate

The study was reviewed and approved by our ethics committee (Comitato Etico Interaziendale, Milano area 1); all subjects signed a dedicated informed consent.

\section{Consent for publication}

Not applicable.

\section{Competing interests}

S.R. has received consultancy payments and speaking fee from Bristol-Myers Squibb, Gilead, ViiV Healthcare, Merck Sharp Dohme, ABBvie and Janssen. M.G. has received consultancy payments and speaking fee from Bristol-Myers Squibb, Gilead, ViiV Healthcare, Merck Sharp Dohme, ABBvie, Janssen and Roche. Preliminary data of this study were presented as poster presentation (PE10/ 15) at the 16th European AIDS conference, October 25-27, 2017 Milan, Italy. 


\section{Publisher's Note}

Springer Nature remains neutral with regard to jurisdictional claims in published maps and institutional affiliations.

\section{Author details}

'Infectious Diseases Unit, DIBIC Luigi Sacco - University of Milan, Via G.B. Grassi, 74, 20157 Milan, Italy. ${ }^{2}$ ASST Fatebenefratelli-Sacco, Clinical Pharmacology Unit, Milan, Italy. ${ }^{3}$ E. Medea Scientific Institute, Bosisio Parini, Italy.

Received: 13 December 2017 Accepted: 31 October 2018 Published online: 12 November 2018

\section{References}

1. Milinkovic A, Martínez E. Nevirapine in the treatment of HIV. Expert Rev Anti-Infect Ther. 2004:2:367-73.

2. De Boissieu P, Dramé M, Raffi F, et al. Dat'AIDS study group. Long-term efficacy and toxicity of abacavir/lamivudine/nevirapine compared to the most prescribed ARV regimens before 2013 in a French Nationwide cohort study. Medicine (Baltimore). 2016;95(37):e4890.

3. Reliquet V, Allavena C, Morineau-Le Houssine P, Mounoury O, Raffi F. Twelve-year experience of nevirapine use: benefits and convenience for long-term management in a French cohort of HIV-1-infected patients. HIV Clin Trials. 2010:11(2):110-7.

4. Llibre JM, Bravo I, Ornelas A, et al. Effectiveness of a treatment switch to Nevirapine plus Tenofovir and Emtricitabine (or lamivudine) in adults with HIV-1 suppressed viremia. PLoS One. 2015;10(6):e0128131.

5. Patel SM, Johnson S, Belknap SM, et al. Serious adverse cutaneous and hepatic toxicities associated with nevirapine use by non-HIV-infected individuals. J Acquir Immune Defic Syndr. 2004 Feb 1;35(2):120-5.

6. Stern JO, Robinson PA, Love J, et al. A comprehensive hepatic safety analysis of nevirapine in different populations of HIV infected patients. J Acquir Immune Defic Syndr. 2003:34(Suppl. 1):S21-33.

7. Dieterich DT, Robinson PA, Love J, Stern JO. Drug-induced liver injury associated with the use of nonnucleoside reverse-transcriptase inhibitors. Clin Infect Dis. 2004;38(Suppl. 2):S80-9.

8. Wu PY, Cheng CY, Liu CE, et al. Multicenter study of skin rashes and hepatotoxicity in antiretroviral-naïve HIV-positive patients receiving nonnucleoside reverse-transcriptase inhibitor plus nucleoside reversetranscriptase inhibitors in Taiwan. PLoS One. 2017 Feb 21;12(2):e0171596.

9. Kesselring AM, Wit FW, Sabin CA, Lundgren JD, Gill MJ, Gatell JM, et al. Risk factors for treatment-limiting toxicities in patients starting nevirapinecontaining antiretroviral therapy. AIDS. 2009;23:1689-99.

10. Mocroft A, Staszewski S, Weber R, et al. EuroSIDA study group. Risk of discontinuation of nevirapine due to toxicities in antiretroviral-naïve and -experienced HIV-infected patients with high and low CD4+ T-cell counts. Antivir Ther. 2007;12(3):325-33.

11. Van Welzen B, Mudrikova T, Arends J, Hoepelman A. No increased risk of hepatotoxicity in long-term use of nonnucleoside reverse transcriptase inhibitors in HIV-infected patients. HIV Med. 2012;13(7):448-52.

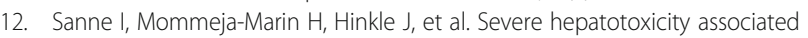
with nevirapine use in HIV-infected subjects. J Infect Dis. 2005;191(6):825-9.

13. Riska P, Lamson M, MacGregor T, Sabo J, Hattox S, Pav J, Keirns J. Disposition and biotransformation of the antiretroviral drug nevirapine in humans. Drug Metab Dispos. 1999;27:895-901.

14. Bertrand J, Chou M, Richardson DM, et al. ANRS 12154 study group. Multiple genetic variants predict steady-state nevirapine clearance in HIV-infected Cambodians. Pharmacogenet Genomics. 2012;22(12):868-76.

15. Penzak SR, Kabuye G, Mugyenyi P, et al. Cytochrome P450 2B6 (CYP2B6) G516T influences nevirapine plasma concentrations in HIV-infected patients in Uganda. HIV Med. 2007;8(2):86-91.

16. Wyen $\mathrm{C}$, Hendra $\mathrm{H}$, Vogel $\mathrm{M}$, et al. Impact of CYP2B6 983T>C polymorphism on non-nucleoside reverse transcriptase inhibitor plasma concentrations in HIV-infected patients. J Antimicrob Chemother. 2008;61:914-8.

17. Rotger $\mathrm{M}$, Colombo S, Furrer $\mathrm{H}_{\text {, et }}$ al. Influence of CYP2B6 polymorphism on plasma and intracellular concentrations and toxicity of efavirenz and nevirapine in HIV-infected patients. Pharmacogenet Genomics. 2005;15:1-5.

18. Gozalo C, Grard L, Loiseau P, et al. For the ANRS 081 study group pharmacogenetics of toxicity, plasma trough concentration and treatment outcome with Nevirapine-containing regimen in anti-retroviral-nave HIV- infected adults: an exploratory study of the TRIANON ANRS 081 trial. Basic \& Clinical Pharmacology \& Toxicology. 2011;109:513-20.

19. Haas DW, Bartlett JA, Andersen JW, et al. Pharmacogenetics of nevirapineassociated hepatotoxicity: an adult AIDS Clinical Trials Group collaboration. Clin Infect Dis. 2006;43:783-6.

20. Ciccacci C, Borgiani P, Ceffa S, et al. Nevirapine-induced hepatotoxicity and pharmacogenetics: a retrospective study in a population from Mozambique. Pharmacogenomics. 2010;11:23-31.

21. Danan G, Teschke R. RUCAM in drug and herb induced liver injury: the update. Int J Mol Sci. 2016;17(1):14.

22. Brück S, Witte $S$, Brust J, et al. Hepatotoxicity in patients prescribed efavirenz or nevirapine. Eur J Med Res. 2008;13:343-8.

23. Bekker $Z$, Walubo A, du Plessis JB. The role of the immune system in Nevirapine-induced subclinical liver injury of a rat model. ISRN Pharmaceutics. 2012:2012:932542.

24. Núñez M. Hepatotoxicity of antiretrovirals: incidence, mechanisms and management. J Hepatol. 2006:44(1 Suppl):S132-9 Epub 2005 Nov 28.

25. Sulkowski MS, Thomas DL, Chaisson RE, Moore RD. Hepatotoxicity associated with antiretroviral therapy in adults infected with human immunodeficiency virus and the role of hepatitis $C$ or B virus infection. JAMA. 2000;283:74-80

26. Vogel M, Bertram N, Wasmuth JC, Wyen C, Voigt E, Schwarze-Zander C, Sudhop T, Fätkenheuer G, Rockstroh JK, Reichel C. Nevirapine pharmacokinetics in HIV-infected and HIV/HCV-coinfected individuals. J Antimicrob Chemother. 2009 May;63(5):988-91.

27. Wen $B$, Chen Y, Fitch WL. Metabolic activation of nevirapine in human liver microsomes: dehydrogenation and inactivation of cytochrome P450 3A4. Drug Metab Dispos. 2009 Jul;37(7):1557-62.

28. Schipani A, Wyen C, Mahungu T, et al. German competence network for HIV/AIDS. Integration of population pharmacokinetics and pharmacogenetics: an aid to optimal nevirapine dose selection in HIVinfected individuals. J Antimicrob Chemother. 2011;66(6):1332-9.

29. Mahungu T, Smith C, Turner F, et al. Cytochrome P450 2B6 516G-->T is associated with plasma concentrations of nevirapine at both $200 \mathrm{mg}$ twice daily and $400 \mathrm{mg}$ once daily in an ethnically diverse population. HIV Med. 2009 May; 10(5):310-7.

30. Giacomelli A, Rusconi S, Falvella FS, et al. Clinical and genetic determinants of nevirapine plasma trough concentration. SAGE Open Med. 2018;6: 2050312118780861.

31. Yuan J, Guo S, Hall D, et al. Nevirapine Toxicogenomics study team. Toxicogenomics of nevirapine-associated cutaneous and hepatic adverse events among populations of African, Asian, and European descent. AIDS. 2011;25(10):1271-80.

32. Owen A, Pirmohamed M, Khoo HS, Back DJ. Pharmacogenetics of HIV therapy. Pharmacogenet Genomics. 2006;16:693-703.

33. Zanger UM, Schwab M. Cytochrome P450 enzymes in drug metabolism: regulation of gene expression, enzyme activities, and impact of genetic variation. Pharmacol Ther. 2013 Apr;138(1):103-41.

34. Kitzmiller JP, Sullivan DM, Phelps MA, Wang D, Sadee W. CYP3A4/5 combined genotype analysis for predicting statin dose requirement for optimal lipid control. Drug Metabol Drug Interact. 2013;28(1):59-63.

Ready to submit your research? Choose BMC and benefit from:

- fast, convenient online submission

- thorough peer review by experienced researchers in your field

- rapid publication on acceptance

- support for research data, including large and complex data types

- gold Open Access which fosters wider collaboration and increased citations

- maximum visibility for your research: over $100 \mathrm{M}$ website views per year

At $\mathrm{BMC}$, research is always in progress.

Learn more biomedcentral.com/submission 